\title{
Feasibility of computed tomography based thermometry during interstitial laser heating in bovine liver
}

\author{
G. D. Pandeya - J. H. G. M. Klaessens • \\ M. J. W. Greuter • B. Schmidt • T. Flohr • \\ R. van Hillegersberg $\cdot$ M. Oudkerk
}

Received: 30 September 2010 /Revised: 17 January 2011 /Accepted: 20 January 2011 /Published online: 24 March 2011

(C) The Author(s) 2011. This article is published with open access at Springerlink.com

\begin{abstract}
Objectives To assess the feasibility of computed tomography (CT) based thermometry during interstitial laser heating in the bovine liver.

Methods Four freshly exercised cylindrical blocks of bovine tissue were heated using a continuous laser of $\mathrm{Nd}$ : YAG (wavelength: $1064 \mathrm{~nm}$, active length: $30 \mathrm{~mm}$, power: 10-30 W). All tissues were imaged at least once before and 7 times during laser heating using $\mathrm{CT}$ and temperatures were simultaneously measured with 5 calibrated thermal sensors. The dependency of the average CT numbers as a function of temperature was analysed with regression analysis and a CT thermal sensitivity was derived.

Results During laser heating, the growing hypodense area was observed around the laser source and that area showed an increase as a function of time. The formation of hypodense area was caused by declining in CT numbers at increasing temperatures. The regression analysis showed
\end{abstract}

G. D. Pandeya $(\varangle) \cdot$ M. J. W. Greuter $\cdot$ M. Oudkerk

Department of Radiology, UMC Groningen,

University of Groningen,

Hanzeplein 1, PO Box 30001, 9700 RB Groningen,

The Netherlands

e-mail: g.d.pandeya@rad.umcg.nl

e-mail: dearganga@gmail.com

G. D. Pandeya $\cdot$ B. Schmidt $\cdot$ T. Flohr

H IM CT PLM-E PA, Siemens AG,

Forchheim, Germany

J. H. G. M. Klaessens

Department of Medical technology and Clinical Physics,

UMC Utrecht,

Utrecht, The Netherlands

R. van Hillegersberg

Department of Surgical Oncology, UMC Utrecht,

Utrecht, The Netherlands an inverse linear dependency between temperature and average CT number with $-0.65 \pm 0.048 \mathrm{HU} /{ }^{\circ} \mathrm{C}\left(\mathrm{R}^{2}=0.75\right)$ for the range of $18-85^{\circ} \mathrm{C}$ in bovine liver.

Conclusions The non-invasive CT based thermometry during interstitial laser heating is feasible in the bovine liver. CT based thermometry could be further developed and may be of potential use during clinical LITT of the liver.

Keywords Computed tomography · Non-invasive thermometry - Laser interstitial thermometry - Ablation . Thermal sensitivity

\section{Introduction}

Thermal ablative techniques such as laser, radiofrequency (RF), and microwave have gained interest as effective and safe alternatives for many patients [1-3]. However, laserinduced interstitial thermotherapy (LITT) is capable of destroying not only liver metastases with an improved survival rate, but also other abdominal tumours $[4,5]$. Despite minor complications such as hepatic abscesses, bile duct injury and liver segmental infarction, low complication rates $(<2 \%)$ were reported for LITT [6, 7]. The complete tumour ablation is usually hampered by limited temperature information during LITT. Thus, a method to extract temperature information is required and especially, method needs to be non-invasive approach. Such method may improve the efficiency of LITT.

Laser-induced interstitial thermotherapy is mostly performed via interstitial fibres with 10 to $40 \mathrm{~mm}$ cylindrical diffusing tips [8], using a Nd:YAG (Neodymium:YttriumAluminium-Garnet) laser at $1064 \mathrm{~nm}$ because of its optimal penetration at the near-infrared range of the spectrum [9]. 
The laser heating by direct penetration is increased in malignant tissue than normal tissue because of a decrease in anisotropy, absorption and scattering coefficients. Temperatures above $60^{\circ} \mathrm{C}$ will cause rapid coagulative necrosis, temperatures above $100^{\circ} \mathrm{C}$ will cause vaporisation [9], and temperatures above $300^{\circ} \mathrm{C}$ will cause carbonisation. This carbonisation reduces optical penetration and heat conduction and, therefore, limits the size of the ablation area. The use of saline-cooled sheaths prevents carbonisation and allows for higher laser powers up to $50 \mathrm{~W}$ compared with $5 \mathrm{~W}$ without cooling sheaths [10].

During LITT, non-invasive temperature monitoring is required to achieve complete tumour necrosis without damaging critical anatomical structures [11]. Moreover, this process is essential to avoid local recurrence. Recently, various techniques such as ultrasound imaging [12], MR imaging $[13,14]$ and microwave radiometry [15] have been under investigation for non-invasive thermometry. Among these imaging techniques, MR thermal imaging has shown a temperature accuracy of $\pm 1^{\circ} \mathrm{C}$. However, MR has relatively long acquisition times and is therefore sensitive to motion and misregistration artefacts $[16,17]$. Although few studies $[18,19]$ reported the temperature dependency using modern Computed Tomography (CT) but CT has not been explored to monitor temperatures during LITT in clinical practice.

Therefore, the aim of the present study is to assess the feasibility of non-invasive CT based thermometry during laser heating of liver tissue in an ex-vivo setting.

\section{Materials and methods}

The study was conducted after obtaining approval from the institutional ethical committee for animal care. Bovine livers were extracted from animals and four cylindrical blocks of liver tissue with $90 \mathrm{~mm}$ in diameter and approximately $50 \mathrm{~mm}$ in thickness were dissected within 12 hour of sacrifice. Each circular block of liver tissue was placed into a Perspex cylinder of $90 \mathrm{~mm}$ in internal diameter (Fig. 1).

Laser heating was performed with an Nd:YAG laser (TT Yag-80; Trumpf Medizine Systeme, Umkirch, Germany) at a wavelength of $1064 \mathrm{~nm}$. The laser light was delivered through a quartz fibre with a core diameter of $400 \mu \mathrm{m}$ and was diffused using an applicator with a length of $30 \mathrm{~mm}$ (Microflexx 30, KLS Martin GmbH, Umkirch, Germany). The fibre was placed into a cooling sheath (Lightcath, Trumpf Medizine Systeme, Umkirch, Germany). The cooling sheath with the laser fibre was inserted through the central hole (diameter: $5 \mathrm{~mm}$ ) in the top of the Perspex cylinder into the liver tissue at a depth of $50 \mathrm{~mm}$. Each of the four liver tissue blocks were heated using laser with a power from approximately 10 to $30 \mathrm{~W}$ in $5 \mathrm{~W}$ interval. Laser heating was put off when temperature measured by thermal sensor 1 was reached $85^{\circ} \mathrm{C}$ in each experiment.

Five calibrated thermocouple (NiCr-Ni) thermal sensors of $0.25 \mathrm{~mm}$ in diameter were inserted through holes $(1 \mathrm{~mm}$ in diameter) in the top of the Perspex cylinder at 10, 15, 20, 25 and $30 \mathrm{~mm}$ from the laser fibre at a depth of approximately $30 \mathrm{~mm}$ in the liver tissue (Fig. 1). All thermal sensors were connected to a data logger (TopMessage, Delphine Technology, Germany) and real-time temperature was recorded and stored in a personal computer. During each of the four laser heating experiments, the temperature recorded by thermal sensor 1 was referenced to monitor power given to laser when temperature rose from room temperature $\left(18^{\circ} \mathrm{C}\right)$ up to a maximum of $85^{\circ} \mathrm{C}$.

Before and during each of the four laser heating experiments, each block of liver tissue was examined using multidetector CT (SOMATOM Definition; Siemens AG, Forchheim, Germany). The CT examinations were done in a sequential mode using $120 \mathrm{kVp}$ and $200 \mathrm{mAs}$ in single source mode, a collimation of $12 \times 1.2 \mathrm{~mm}$, and a rotation time of $500 \mathrm{~ms}$. The acquired images were adjacently reconstructed with a slice thickness of $1.2 \mathrm{~mm}$, a field of view of $300 \mathrm{~mm}$, and a B31s smooth kernel on a dedicated workstation (Syngo, Siemens AG, Forchheim, Germany). In each CT examination, the tissue was imaged at least 1 time before and 7 times during laser heating at the interval of about $5 \mathrm{~min}$.

The radiation dose was read from the workstation of the CT system for each of the four laser heating experiments. The average dose per CT and per examination during each experiments was calculated.

On the CT images, circular region of interests (ROI) with an area of approximately $100 \mathrm{~mm}^{2}$ were manually drawn around the tip of each of the five thermal sensors. From each of these five ROIs the average $\mathrm{CT}$ number and standard deviation were calculated. A linear regression analysis was performed using all measurement points to determine the dependency of the average CT number on temperature and to derive the CT thermal sensitivity. The accuracy of the fit was tested by calculating R-square coefficient $\left(\mathrm{R}^{2}\right)$. The data were analysed using statistical software (SPSS 16.0; SPSS, Chicago, IL, USA).

\section{Results}

During laser heating, a growing hypodense area on the CT images was observed around the laser source and that area showed an increase as a function of time shown in Fig. 2. The formation of hypodense area was caused by declining in $\mathrm{CT}$ numbers at increasing temperatures during laser heating of bovine liver tissue. 
Fig. 1 Schematic set up of the bovine liver tissue inside the Plexiglas cylinder. The laser fibre $(\mathrm{Nd}: \mathrm{YAG}$, continuous wave of wavelength:1064 $\mathrm{nm}$, diffusing length: $30 \mathrm{~mm}$ ) with cooling sheath and saline flush was inserted from the top of the cylinder and 5 thermal sensors ( $\mathrm{NiCr}-\mathrm{Ni}$, diameter: $0.25 \mathrm{~mm}$ ) were inserted at distances of 10 , $15,20,25$ and $30 \mathrm{~mm}$ from the laser fibre
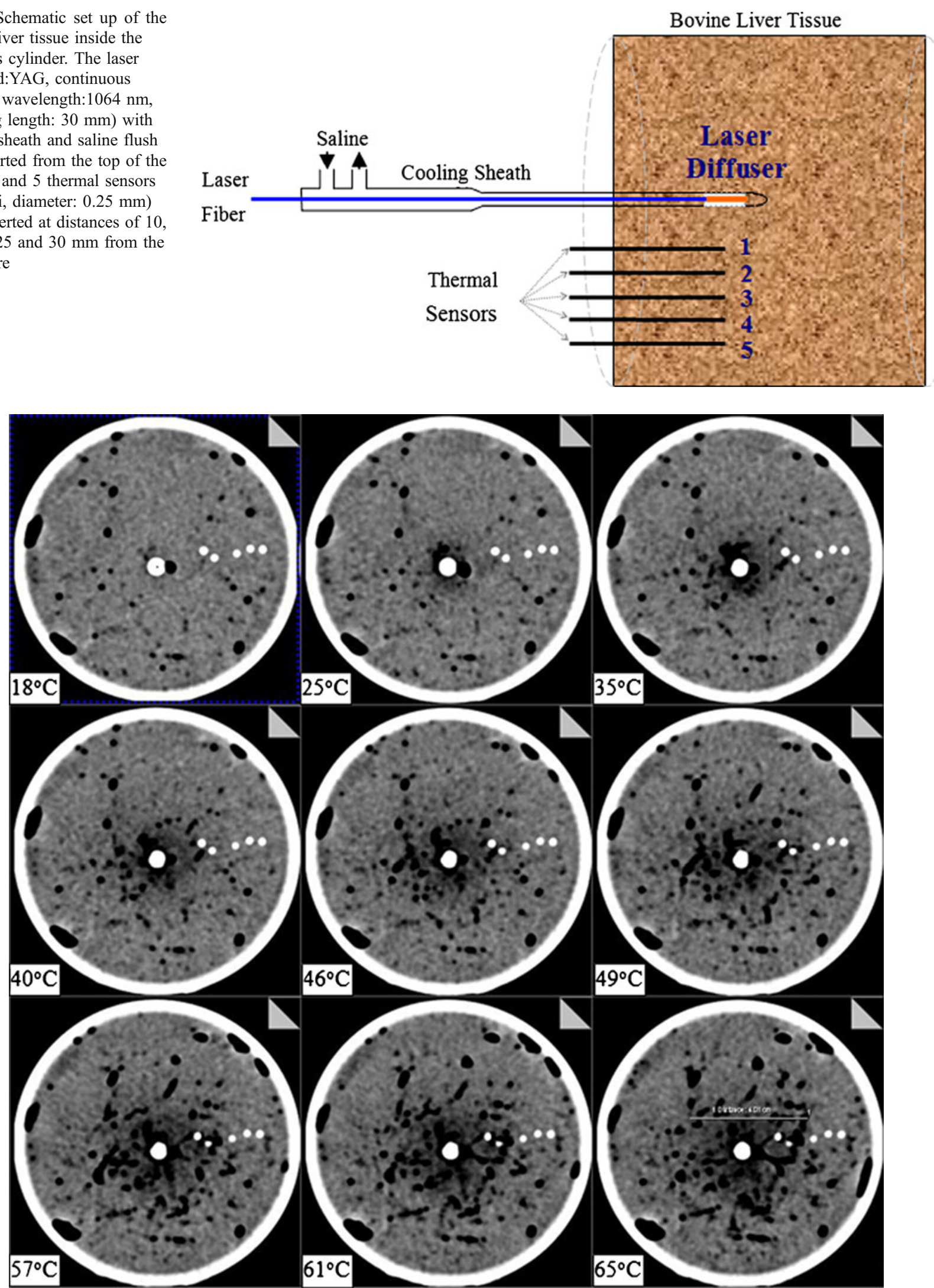

Fig. 2 Example of the increase in a hypodense area during laser heating experiment in the bovine liver tissue. The temperature measured at thermal sensor 1 during experiment was shown on each CT image. The white ring, the central white spot and the five small white spots are the Plexiglas cylinder, the laser fibre with cooling system and the thermal sensors respectively. The window/level setting of the images was 100/80 
The regression analysis showed an inverse linear relation between the average $\mathrm{CT}$ number and temperature with $-0.65 \pm 0.05 \mathrm{HU} /{ }^{\circ} \mathrm{C}\left(\mathrm{R}^{2}=0.78\right)$ (Fig. 3$)$ which is a $\mathrm{CT}$ thermal sensitivity for the range of $18^{\circ} \mathrm{C}$ to $85^{\circ} \mathrm{C}$. In the Fig. 3, above 96\% measurement points remained within $95 \%$ prediction interval. However, few of measured points were sparsely distributed at higher temperature due to $\mathrm{CT}$ noise. The image noise showed an increase from 4 to $20 \mathrm{HU}$ when the temperature of the tissue was increased from room temperature to $85^{\circ} \mathrm{C}$.

The radiation dose delivered during each $\mathrm{CT}$ acquisition was approximately $15 \mathrm{mGy}$. Depending on the number of CTs that were made during each of the four laser heating experiments, the dose ranged from $92 \mathrm{mGy}(8 \mathrm{CTs})$ to 231 mGy (15 CTs).

\section{Discussion}

In this study, the formation of hypodense area was observed around laser source which ensured the thermal shift of CT number during laser heating of liver tissue. An inverse linear dependency of $\mathrm{CT}$ numbers on temperature was found with a CT thermal sensitivity of $0.65 \pm 0.05 \mathrm{HU} /{ }^{\circ} \mathrm{C}$ $\left(\mathrm{R}^{2}=0.78\right)$. The decline in $\mathrm{CT}$ numbers depends on temperature change on tissue with its contents. The spatial and temporal distribution of the temperature in the liver was also shown by declining CT numbers on the CT images taken at different time points during laser heating. Thus, the present study showed in principle that non-invasive $\mathrm{CT}$ temperature measurement can be carried out during LITT.
The previous studies $[20,21]$ showed different values of thermal sensitivity using early CT systems and experimental parameters. Fallone et al. [20] measured thermal sensitivity of $-0.45 \mathrm{HU} /{ }^{\circ} \mathrm{C}$ where tissue was heated using water bath and imaged using early CT system at $6 \mathrm{sec}$ of rotation time and $15 \mathrm{~mm}$ of slice thickness. Jenne et al. [21] measured thermal sensitivity of $-0.43 \mathrm{HU} /{ }^{\circ} \mathrm{C}$ where tissue was heated using focused ultrasound and imaged using CT system at $1.5 \mathrm{sec}$ of rotation time and $8 \mathrm{~mm}$ of slice thickness. Although these studies [20, 21] showed a linear dependency of the $\mathrm{CT}$ number on temperature under different experimental parameters, those results can not be retained into the present $\mathrm{CT}$ system of below $0.5 \mathrm{sec}$ of rotation time and below $0.3 \mathrm{~mm}$ of slice thickness, and heating techniques like laser ablation. The high temporal and spatial resolutions of $\mathrm{CT}$ system may provide the accurate temperature information by improving image detail without a significant increase in radiation dose and could assist to improve the temperature resolution. So, this study investigates the potential of current $\mathrm{CT}$ for noninvasive thermometry during laser heating.

Although alternative imaging techniques like MRI, US are under investigation for non-invasive temperature measurement during ablation, these techniques have a relatively long acquisition time or a relatively low spatial resolution [12, 17, 22]. Currently, CT systems are available with high spatial and temporal resolution which enables small changes in the treated tissue to be depicted with 3-dimensional isotropic resolution [23]. Nevertheless, radiation dose delivered during imaging could be additional concerns in clinical practice. The radiation delivered during this experiment was under $231 \mathrm{mGy}$ which is far below skin erythema threshold dose of
Fig. 3 Average CT number in a ROI close to the tip of the five thermal sensors as a function of temperature. The central line in the graph represents a linear fit and the two dotted lines represent the $95 \%$ prediction interval

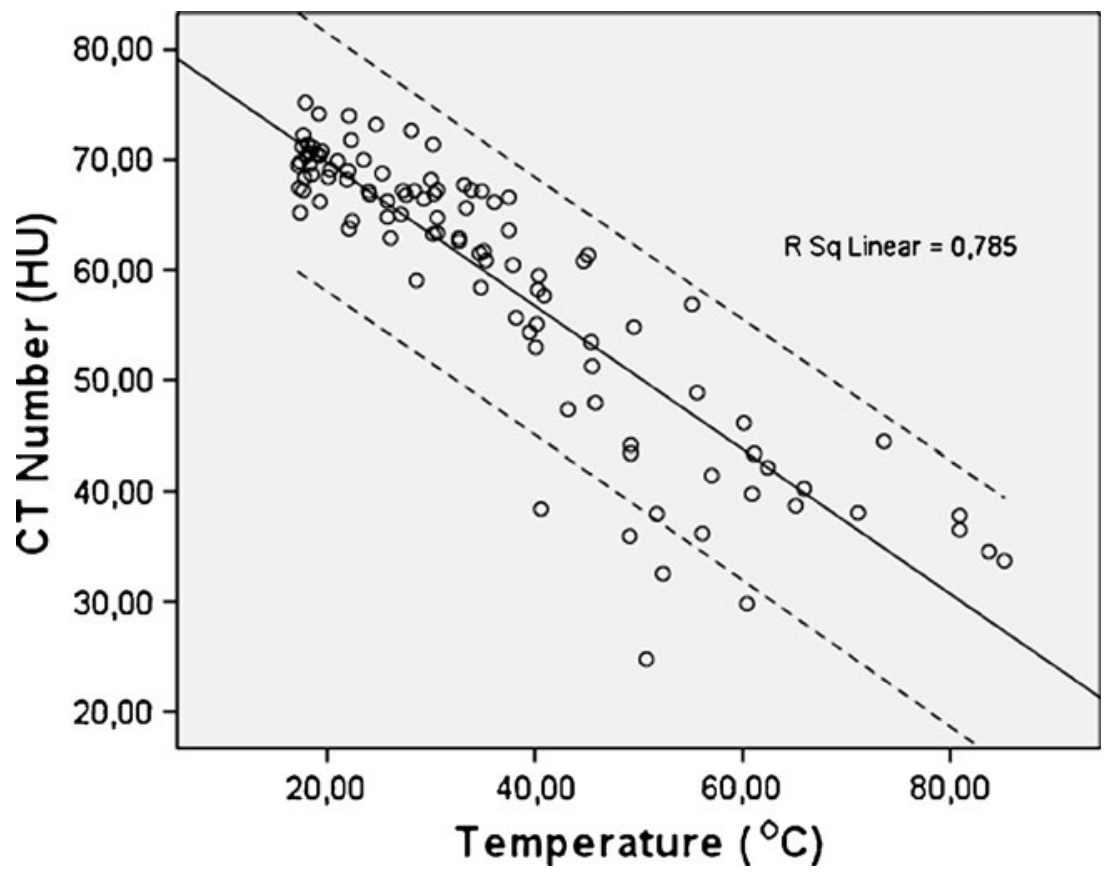


200 cGy. The dose can be further reduced by limiting the number of scans and by optimising imaging technique.

High temperatures in tissue cause excessive physical forces between molecules, which can lead to various cell destructive processes and to thermal cell damage [24, 25]. It has been shown that thermal damage does not depend on cell size or shape but only on the molecular structure and the strength of chemical bonds in the cell [26]. Therefore, similar effects of thermal damage in different tissue types are expected [24]. Nevertheless, local tissue properties, in particular perfusion, have a significant impact on the extent of thermal damage. Highly perfused tissue and large vessels may act as a heat sink, as laser light is absorbed by erythrocytic heme, and heat is transported from the local tissue area to the peripheral tissue [27]. The effect of perfusion makes native liver parenchyma relatively more resilient to laser induced thermal damage than tumour tissue. In addition, this effect can cause a more asymmetric temperature distribution and a more irregular necrosis zone [28] than the approximately radial symmetric temperature distribution shown in the present study.

There are a few limitations to the present study, which may affect the result. First, the heat distribution might be affected by the presence of the five thermocouples in the necrosis zone. As the heat conduction in the thermocouples was minimised because of the use of mineral-insulated materials a minor influence on the heat distribution during the laser heating experiment is expected because of the presence of the thermocouples. In addition, no interference between laser light and thermocouple sensors was observed distinctive to the optical sensors. Second, although the CT images were influenced by beam hardening, this effect mainly influenced the CT numbers in the direct vicinity of the cooling sheath. Temperature information in the direct vicinity of the cooling sheath is less necessary than at a larger distance. Therefore, it is estimated that beam hardening only had a minor influence on the present results. Third, the change in CT number after heating was not included in this study. Although, the main concerned is to determine the area of necrosis by detecting the region with temperature above $60^{\circ} \mathrm{C}[9,29]$ during heating, further study is necessary to investigate the reversible effect. Fourth, vaporisation during laser heating might hamper the heat conduction and subsequently affects the image quality. In order to reduce this effect a cooling sheath was used [10]. Moreover, because of the relatively small size of the air bubbles and use of relatively high spatial resolution CT system, we estimate that the effect caused by the air bubbles has a minor effect on our study outcome. Finally, the ex-vivo tissue does not resemble an in-vivo tissue situation because of the effects of local physiological processes like perfusion and surrounding heterogeneous structures including bones. Therefore, these effects could increase the noise and cause asymmetric heat distribution [30]. These effects need to be further evaluated in animal studies before implementation in clinical practice is possible.
To the best of our knowledge, the present study is the first study in which liver tissue was heated using laser and in which temperature was measured non-invasively with high-end CT technology. From this study, it is concluded that the non-invasive CT based thermometry during interstitial laser heating is feasible in an ex-vivo bovine liver. The thermal sensitivity may be used to predict temperature development during LITT. Therefore, CT based thermometry may be of potential use during LITT.

Open Access This article is distributed under the terms of the Creative Commons Attribution Noncommercial License which permits any noncommercial use, distribution, and reproduction in any medium, provided the original author(s) and source are credited.

\section{References}

1. Ferrari FS, Megliola A et al (2007) Treatment of small HCC through radiofrequency ablation and laser ablation. Comparison of techniques and long-term results. Radiol Med (Torino) 112:377-393

2. Fischer K, Gedroyc W, Jolesz FA (2010) Focused ultrasound as a local therapy for liver cancer. Cancer J 16:118-124

3. Martin RC, Scoggins CR, McMasters KM (2010) Safety and efficacy of microwave ablation of hepatic tumors: a prospective review of a 5 year experience. Ann Surg Oncol 17:171-178

4. Vogl TJ, Eichler K, Straub R et al (2001) Laser-induced thermotherapy of malignant liver tumors: general principals, equipment(s), procedure(s) - side effects, complications and results. Eur J Ultrasound 13:117-127

5. Mack MG, Straub R, Eichler K et al (2001) MR-guided laserinduced thermotherapy in recurrent extrahepatic abdominal tumors. Eur Radiol 11:2041-2046

6. Vogl TJ, Straub R, Eichler K, Woitaschek D, Mack MG (2002) Malignant liver tumors treated with MR imaging-guided laserinduced thermotherapy: experience with complications in 899 patients (2520 lesions). Radiology 225:367-377

7. Arienti V, Pretolani S et al (2008) Complications of laser ablation for hepatocellular carcinoma: a multicenter study. Radiology 246:947-955

8. Muralidharan V, Malcontenti-Wilson C, Christophi C (2002) Interstitial laser hyperthermia for colorectal liver metastases: the effect of thermal sensitization and the use of a cylindrical diffuser tip on tumor necrosis. J Clin Laser Med Surg 20:189-196

9. Gough-Palmer AL, Gedroyc WM (2008) Laser ablation of hepatocellular carcinoma-A review. World J Gastroenterol 14:7170-7174

10. Vogl TJ, Straub R et al (2004) MR-guided laser-induced thermotherapy (LITT) of liver tumors: experimental and clinical data. Int J Hyperthermia 20:713-724

11. Dodd GD, Soulen MC et al (2000) Minimally invasive treatment for malignant hepatic tumors: at the threshold of a major breakthrough. Radiographics 20:9-27

12. Seip R, Ebbini ES (1995) Noninvasive estimation of tissues temperature response to heating fields using diagnostic ultrasound. IEEE Trans Biomed Eng 42:828-39

13. Weidensteiner C, Quesson B et al (2003) Real time MR temperature mapping of rabbit liver in vivo during thermal ablation. Magn Reson Med 50:322-330 
14. Lepitit-Coiffee M, Quesson B et al (2006) Real time monitoring of radiofrequency ablation of rabbit liver by respiratory gated quantitative temperature MRI. J Magn Reson Imaging 24:152-159

15. Wang SS, VanderBrink BA et al (2000) Microwave radiometric thermometry and its potential applicability to ablative therapy. J Interv Card Electrophysiol 4:295-300

16. Dick EA, Wragg P et al (2003) Feasibility of abdomino-pelvic T1weighted real-time thermal mapping of laser ablation. J Magn Reson Imaging 17:197-205

17. De Senneville BD, Roujol S et al (2010) Motion correction in MR thermometry of abdominal organs: a comparison of the referenceless vs the multibaseline approach. Magn Reson Med 64:1373-1381

18. Homolka P, Gahleitner A, Nowotny R (2002) Temperature dependence of $\mathrm{HU}$ values for various water equivalent phantom materials. Phys Med Biol 47:2917-2923

19. Bruners P, Levitt E et al (2010) Multi-slice computed tomography: a tool for non-invasive temperature measurement? Int J Hyperthermia 26:359-365

20. Fallone BG, Moran PR et al (1982) Noninvasive thermometry with a clinical x-ray CT scanner. Med Phys 9:715-721

21. Jenne JW, Bahner M, et al (1997) CT on-line monitoring of HIFU therapy. Proc IEEE Ultrason Symp 1377-1380

22. Goldberg SN, Dupuy DE (2001) Image-guided radiofrequency tumor ablation: challenges and opportunities-Part I. J Vasc Interv Radiol 12:1021-1032
23. Ueno J, Murase T et al (2004) Three-dimensional imaging of thoracic diseases with multi-detector row CT. J Med Invest 51:163-170

24. Lee RC, Astumian RD (1996) The physicochemical basis for thermal and non-thermal 'burn' injuries. Burns 22:509-519

25. Dewey WC (1989) Failla memorial lecture. The search for critical cellular targets damaged by heat. Radiat Res 120:191-204

26. Breen MS, Breen MB et al (2007) MRI-guided thermal ablation therapy: model and parameters estimates to predict cell death from MR thermometry images. Ann Biomed Eng 35:1391-1403

27. Whelan WM, Wyman DR, Wilson BC (1995) Investigations of large vessel cooling during interstitial laser heating. Med Phys 22:105-115

28. Jiang SC, Zhang XX (2005) Dynamic modelling of photothermal interactions for laser-induced interstitial thermotherapy: parameter sensitivity analysis. Lasers Med Sci 20:122131

29. Goldberg SN, Gazelle GS, Halpern EF et al (1996) Radiofrequency tissue ablation: importance of local temperature along the electrode tip exposure in determining lesion shape and size. Acad Radiol 3:212-218

30. Bydder GM, Kreel L (1979) The temperature dependence of computed tomography attenuation values. J Comput Assist Tomogr 3:506-510 